Powers of rat destruction under Rat Order (Ministry of Food) are valuable as anti-plague measures.

Partial fumigation of ships suspected of rat epizootic is to be avoidedi as dangerous.

Methods of rendering a crew on a vessel reasonably safe in presence of a rat infection.

Some diagnostic points in human plague with respect to ship infection.

Series of cases treated at Port of London Sanitary Hospital.

\title{
What is a Systematic Medical Inspection of a Ship ?
}

By J. Wright MAsox, M.B., C.M., D.P.H., M.R.C.S.E., Medical Officer of Health, City and Port of Kingston-upon-Hull. (Fellow).

\section{(ABSTRaCt.)}

THE work of checking the spread of infectious disease aboard ship and preventing its importation is the primary duty of all Port Sanitary Authorities. It is performed in precisely the same manner as on shore. The notifiable infectious diseases coming under sanitary control may, for administrative purposes, be divided into two categories: those diseases which are endemic in this country, such as scarlatina, diphtheria, measles, typhoid fever, \&c., and those endemic in foreign countries, as, for example, plague, cholera, and yellow fever.

By far the most important preventive measures which have hitherto acted most successfully in keeping plague and cholera out of this country have reference to the coast, but other valuable measures have been (1) the Orders prohibiting the importation of rags from all infected ports; (2) the Order prohibiting the landing of "Filthy and unwholesome aliens," unless they satisfy the Medical Officer of their freedom from disease, and give their names and addresses; (3) the provision of hospital accommodation and facilities for bathing and disinfection at our ports; and ( 4 ) the adoption of every possible precaution.

The provisions of the 1896 Act have supplanted those of quarantine in this country, and are, without doubt, far more successful in practice. The facts which tell against the efficiency of quarantine, the power to enforce which was in operation for 71 years, are certainly sufficiently strong to warrant the universal adoption of our system. The detention of persons on board an infected ship for many days is not a measure calculated to limit the spread of disease, whilst the delays thus caused are ruinous to trade and 
commerce. Even a very vigorous system of quarantine has been known to fail in its purpose.

The Paris Convention of 1911-12 led to the interchange of information of the presence of plague and cholera within the areas of the countries signing the Convention, and provided measures to be taken in these countries with plague-infected rats found on board ship. Such agreements, however, fail in their immediate object by reason of the fact that they influence only those countries usually the most enlightened and the least dangerous as a source of infection. A uniformly high standard of sanitary administration is that which is desired.

The Amended Rat Order (March, 1919) of the Ministry of Food, raises the question as to whether the powers conferred upon Port Sanitary Authorities as Local Authorities under the Order should become permanent as a public health measure rather than one of food preservation.

There is a desire by the Ministry of Health to co-ordinate the duties of Port work which have hitherto been done under the direction of the Local Government Board and the Home Office (as to aliens). The Ministry of Health are anxious to learn that the port authorities would be ready to undertake duties that may be conferred upon them in relation to the thorough medical inspection of all persons who might land, or wish to land, in this country. In the development of the work of the future the port authorities would be looked to for undertaking these additional and important duties. 